\title{
Association of candidate gene polymorphisms and TGF-beta/IL-10 levels with malaria in three regions of Cameroon: a case-control study
}

Tobias O Apinjoh ${ }^{1}$, Judith K Anchang-Kimbi ${ }^{2}$, Clarisse Njua-Yafi ${ }^{3}$, André N Ngwai ${ }^{4}$, Regina N Mugri ${ }^{4}$, Taane G Clark ${ }^{5}$, Kirk A Rockett ${ }^{6}$, Dominic P Kwiatkowski ${ }^{6}$, Eric A Achidi ${ }^{1}{ }^{1 *}$ and in collaboration with The MalariaGEN Consortium

\begin{abstract}
Background: Plasmodium falciparum malaria is one of the most widespread and deadliest infectious diseases in children under five years in endemic areas. The disease has been a strong force for evolutionary selection in the human genome, and uncovering the critical host genetic factors that confer resistance to the disease would provide clues to the molecular basis of protective immunity and improve vaccine development initiatives.

Methods: The effect of single nucleotide polymorphisms (SNPS) and plasma transforming growth factor beta (TGF- $\beta$ ) and interleukin 10 (IL-10) levels on malaria pathology was investigated in a case-control study of 1862 individuals from two major ethnic groups in three regions with intense perennial $P$. falciparum transmission in Cameroon. Thirty-four malaria candidate polymorphisms, including the sickle cell trait $(\mathrm{HbS})$, were assayed on the Sequenom iPLEX platform while plasma TGF- $\beta$ and IL-10 levels were measured by sandwich ELISA.

Results: The study confirms the known protective effect of $\mathrm{HbS}$ against severe malaria and also reveals a protective effect of SNPs in the nitrogen oxide synthase 2 (NOS2) gene against malaria infection, anaemia and uncomplicated malaria. Furthermore, ADCY9 rs 10775349 (additive G) and ABO rs8176746 AC individuals were associated with protection from hyperpyrexia and hyperparasitaemia, respectively. Meanwhile, individuals with the EMR1 rs373533 GT, EMR1 rs461645 CT and RTN3 rs542998 (additive C) genotypes were more susceptible to hyperpyrexia while both females and males with the rs 1050828 and rs 1050829 SNPs of G6PD, respectively, were more vulnerable to anaemia. Plasma TGF- $\beta$ levels were strongly correlated with heterozygosity for the ADCY9 rs2230739 and HBB rs334 SNPs while individuals with the $A B O$ rs8176746 AC genotype had lower IL-10 levels.

Conclusion: Taken together, this study suggests that some rare polymorphisms in candidate genes may have important implications for the susceptibility of Cameroonians to severe malaria. Moreover using the uncomplicated malaria phenotype may permit the identification of novel pathways in the early development of the disease.
\end{abstract}

Keywords: Single nucleotide polymorphism, Severe malaria, Uncomplicated malaria, Cytokines, Children, Ethnicity

\section{Background}

Malaria affects about one quarter of a billion people annually, with up to two-thirds of a million deaths still occurring per year, particularly in sub-Saharan African children below five years of age [1]. Why only a small proportion (1-3\%) of Plasmodium falciparum infections

\footnotetext{
* Correspondence: achidi_e@yahoo.com

'Department of Biochemistry and Molecular Biology, University of Buea, Buea, Cameroon

${ }^{4}$ Department of Medical Laboratory Science, University of Buea, Buea, Cameroon

Full list of author information is available at the end of the article
}

progress to severe or fatal episodes [2] while others remain asymptomatic or develop an uncomplicated illness is not yet fully understood. Epidemiological data indicate that about $25 \%$ of the risk to Plasmodium infection in Africa is determined by human genetic factors [3]. Nevertheless, haemoglobin $\mathrm{S}$, the strongest known resistance genetic factor, explains only $2 \%$ of the total variation [3], suggesting the existence of many unknown protective genes, each individually having small population effects. Single-nucleotide polymorphisms (SNPs) 
comprise a large part of human diversity, and their inheritance may alter susceptibility to disease [4].

Many of the malaria protective associations described to date relate to genes that affect cytokine and toll-like gene expression [5,6], red blood cell (RBC) structure or function [7]. However, there are a number of interesting candidate polymorphisms that have been associated with other infectious diseases and may be linked to malaria pathogenesis. Complement factor 6 (C6), for instance, shows polymorphism resulting in deficiency of the protein [8] although its role in malaria has not been proven. The susceptibility to typhoid fever is associated with a polymorphism in the cystic fibrosis transmembrane conductance regulator (CFTR) [9], while genetic associations of a member of the tripartite motif (TRIM) family with human immunodeficiency virus type 1 infection [10] have been reported. The levels of reticulon 3 (RTN3) is significantly increased in malaria and other infections [11] suggesting that it may be linked to the disease.

The effect of some polymorphisms on malaria pathogenesis still remains controversial. There was no association between intercellular adhesion molecule 1 gene polymorphisms and severe malaria in a West African population [12], although the SNP had earlier been reported to predispose to cerebral malaria in Kenya [13]. The NOS2A-954C allele has been associated with protection from severe malaria in Gabonese individuals $[14,15]$, but studies in The Gambia and Tanzania failed to detect such a disease association [16,17]. Additionally, the NOS2A-1173 T allele which appears, on the basis of measurements in urine and plasma, to be associated with high NO production in children is associated with protection from malarial illness in Tanzania and from severe malarial anaemia in Kenya [18], but no protective effect against severe malaria was detected in The Gambia [17].

Several studies have demonstrated the critical role of anti-inflammatory cytokines in the immuno-pathogenesis of severe malaria anaemia (SMA) and cerebral malaria (CM). Plasmodium chabaudi chabaudi infected mice deficient in interleukin-10 (IL-10) show higher mortality than their normal littermates [19], suggesting a protective role for this cytokine. Furthermore, IL-10 seems to induce and maintain immunity to $P$. falciparum in naturally exposed populations [20]. Importantly, the down regulation of TNF- $\alpha$ production and consequent resistance to severe malaria, has been linked to the ability to produce the immuno-regulatory cytokine, Transforming growth factor (TGF)- $\beta$ [21]. Low levels of IL-10 and TGF- $\beta$ have been associated with severe malaria $[22,23]$. Functional polymorphisms in the promoter and/or coding region(s) of cytokine genes may, therefore, be crucial in the development and clinical course of malaria [5]. Indeed, polymorphisms in genes encoding IL-10 [6,24] have been associated with susceptibility to malaria, although their functional role in severe malaria still remains open to question. How the levels of these cytokines vary in different haemoglobin $\beta$-globin and other malaria candidate SNP genotypes, therefore, warrants further investigation.

Case-control studies have been vital in detecting several genes associated with malaria or severe malaria [6,25-27]. However, some reports have been contradictory, due partly, to the analysis of small sample numbers, and hence limited statistical power. Furthermore, differences in transmission intensities or other epidemiologic characteristics at the different sites and ethnicities may affect the detection of modest effects of susceptibility or resistance genes. Some rare SNPs were investigated in a case-control study among 971 children with malaria and 891 unmatched apparently healthy control school children and blood bank donors in a bid to identify novel ones that may be linked to malaria and TGF- $\beta$ and IL-10 levels.

\section{Methods \\ Study area}

This cross-sectional study was conducted in four towns distributed in three regions of Cameroon, namely: Yaounde in the Centre; Douala in the Littoral; and Buea and Limbe in the South West. The study sites included hospitals (Bota District Hospital - Limbe, Laquintinie Hospital - Douala, Mother and Child Hospital Yaoundé, Regional Hospital - Limbe and Regional Hospital - Buea) and health centres (Bokova Health Centre, Mount Mary Health Centre - Buea and PMI Down Beach - Limbe). All chosen health facilities, except Mount Mary, were the main government institutions in the selected towns, also receiving patients from surrounding areas. Although malaria is endemic throughout Cameroon, the country has very different geographical and epidemiologic strata that may alter the course of the infection. In general, malaria transmission is intense and perennial in the Centre, Littoral (Coastal), and South Western regions, with peak periods corresponding to the rainy seasons [28].

The Centre region (Yaoundé) is located within the rainforest belt of central Africa [29] and has the Guineatype equatorial climate [28]. This is characterized by fairly constant temperatures [ranging from $17^{\circ} \mathrm{C}$ to $30^{\circ} \mathrm{C}$ $\left(\right.$ mean $\left.\left.=23.1^{\circ} \mathrm{C}\right)\right][30]$, abundant rainfall $(1,500-2,000 \mathrm{~mm})$, with the average relative humidity index ranging from $85 \%$ to $90 \%$, and four distinct seasons: two rainy seasons (March - May/June, September - November) and two dry seasons (December - February, June/July - August). Maximal transmission of malaria occurs during and immediately following the two rainy seasons [28-30]. The Mother and Child Hospital is a referral hospital for children and mothers, located in the heart of the city of 
Yaoundé; it also attracts patients from neighbouring villages such as Simbok and Etoa that are stable, rural, farming communities with fields irrigated by water from the Mefou and Biyeme Rivers. Inhabitants of this region are of the Ewondo tribe and part of the Bantu ethnic group.

The South Western and Littoral regions have a Cameroonian-type equatorial climate characterized by fairly constant temperatures and two seasons: a short dry season (November - March) and a long rainy season (March - November) with abundant precipitation (2,000$10,000 \mathrm{~mm}$ ) [28]. In the Mt Cameroon region of the South West, the mean annual rainfall is $2625 \mathrm{~mm}$, relative humidity is constantly high $(75 \%-80 \%)$, and the temperature varies from $18^{\circ} \mathrm{C}$ in August to $35^{\circ} \mathrm{C}$ in March [31]. Human malaria is meso-endemic during the dry season but becomes hyper-endemic in the rainy season, with incidence peaking in July-October. The prevalence of malaria parasitaemia in the low-altitude areas ranges from $30 \%$ in the dry season to $84 \%$ in the rainy season [32,33]. Plasmodium falciparum accounts for up to $96 \%$ of malaria infections in this area [34], with Anopheles gambiae s.s. the dominant vector [31].

\section{Study design and population}

The study conducted between 2003/05 and 2007/08 involved malaria diagnosed children (aged 1 month 13 years) admitted in nine health facilities in the Centre, Littoral and South West regions of Cameroon [35]. The 971 unrelated sick children sampled included severe and uncomplicated malaria cases, mainly from the Bantu and Semi-Bantu ethnic groups, recruited from the paediatric wards of the hospitals or health centres (Figure 1). In line with WHO guidelines [36], severe malaria was defined by the presence of asexual Plasmodium parasitaemia and at least one of the following conditions: cerebral malaria (CM) [impaired consciousness or unrousable coma (Blantyre coma score $\leq 2$ ) and no record of recent severe head trauma, neurological disease or any other cause of coma]; severe malaria anaemia (SMA) [haemoglobin $<5 \mathrm{~g} / \mathrm{dL}$ or haematocrit $<15 \%$, no cases of severe bleeding or observed convulsions]; hyperpyrexia (axillary temperature $\geq 40^{\circ} \mathrm{C}$ ); hyperparasitaemia ( $>250,000$ parasites $/ \mu \mathrm{L})$; convulsions before/ during admission; respiratory distress (RD) (presence of alar flaring, intercostals or subcostal chest recession, use of accessory muscles of respiration, or abnormally deep respiration) and hypoglycaemia (blood glucose $<2.2 \mathrm{mmol} / \mathrm{L} /$ $40 \mathrm{mg} / \mathrm{dl}$ ). Participants with co-existing severe or chronic medical conditions (e.g. bacterial pneumonia, kwashiorkor) unrelated to a severe malarial infection were excluded. UM was defined as a clinical illness characterized by an axillary temperature $\geq 37.5^{\circ} \mathrm{C}$ associated with a Plasmodium positive blood film, haemoglobin $\geq 8 \mathrm{~g} / \mathrm{dL}$ and full consciousness, in the absence of clinical signs and symptoms of severe malaria and/or evidence of vital organ dysfunction.

Controls $(n=891)$ consisted of apparently healthy children (aged 1-14 years, afebrile and free from any obvious illness) and adults (aged 17-52 years, asymptomatic, from the community) also belonging primarily to the Bantu and Semi-Bantu ethnic groups (Figure 1). Children were recruited during malaria cross-sectional surveys from primary schools located in the South West region (Buea Metropolis) between 2004-2005 and 20072008. Children with parasitaemia and a temperature of $37.5^{\circ} \mathrm{C}$ or above were not recruited as controls. Adults were identified from a blood bank in the Centre region (Mother and Child Hospital - Yaounde) between July and August 2007. These controls were thought to approximate a random sample of the population thus, reflecting the true allele frequency. Data on the Foulbe ethnic group who constitute a significant proportion of

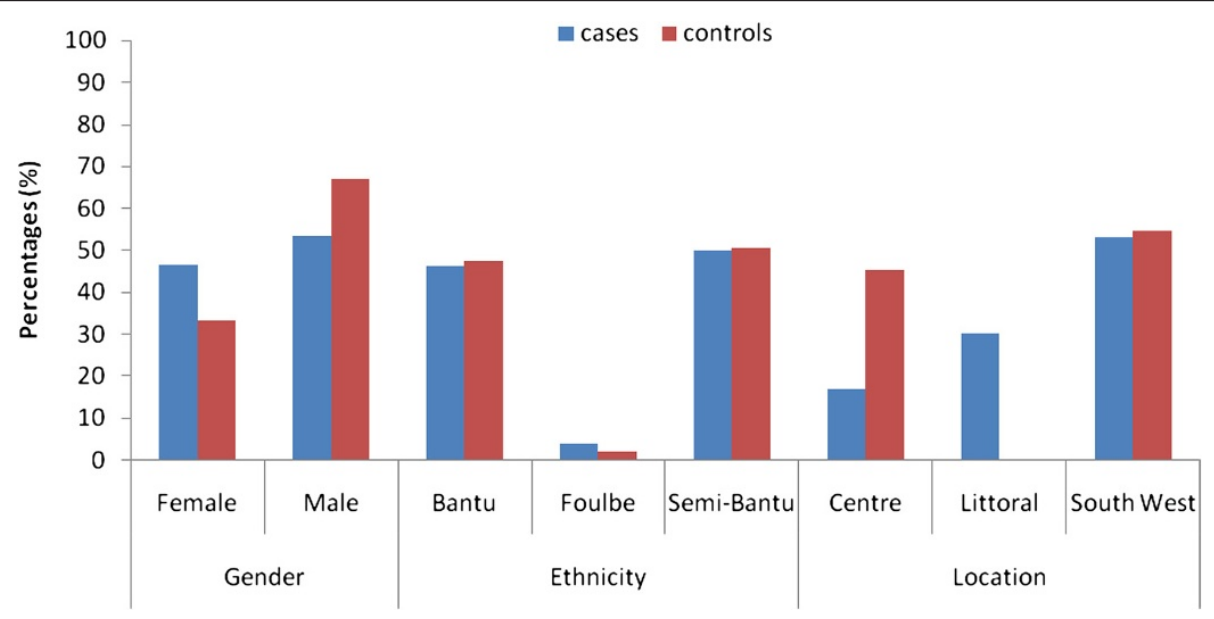

Figure 1 Basic demographic characteristics of the cases $(n=971)$ and controls $(n=891)$ in the study. 
the ethno-demographics of Cameroon were not included in the final analysis because of their small sample size in the study population.

\section{Ethical approvals}

Ethical and administrative clearance for the study was obtained from the University of Buea Institutional Review Board and the South West Regional Delegation of Public Health respectively. Authorization to conduct the surveys in designated primary schools was obtained from the Regional Delegation of Basic Education or the Catholic Education Secretariat of the South West Region. Individuals who fulfilled the specific inclusion criteria and volunteered to participate after adequate sensitisation on the project objectives, methods and possible benefits/risks were enrolled in to the study. A health facility or school was only investigated with the approval of its Director or Head Teacher and study participants were only enrolled if they or their caregivers/guardians gave written informed consent/assent.

\section{Malaria parasitaemia determination}

Thick and thin blood smears were prepared following standard procedures and stained with 5\% Giemsa (Sigma, St. Louis, USA). The malaria parasitaemia status and density were determined under oil immersion with the 100x objective, 10x eyepiece of a binocular Olympus microscope (Olympus Optical Co., Ltd, Japan) while the Plasmodium species was identified on the thin blood smear. A smear was only considered negative if no malaria parasites were seen in 50 high power fields. With each positive smear, the level of parasitaemia was estimated by counting the parasites against at least 200 leucocytes and using the corresponding leucocyte count to calculate the number of parasites/ $\mu$ l blood [37].

\section{Cytokine measurement}

Plasma levels of IL-10 and TGF- $\beta$ were measured in cases and controls by Enzyme-Linked Immunosorbent Assay (ELISA), according to the manufacturer's instructions (Quantikine R\&D systems). Samples were obtained at the time of admission (CM/SMA), outpatient treatment (UM), or enrollment (Controls). The results were expressed in $\mathrm{pg} / \mathrm{ml}$ by reference to standard curves prepared in each plate with recombinant cytokines. In all, the ELISAs, standards/samples were run in duplicates, and tested 10 non-immune Swedish \& British sera were used as negative controls to check that the response was specific to malaria infection.

\section{Selection of SNPs and genotyping}

Genomic DNA was extracted from whole blood or packed cells using the Promega Wizard (Promega Corporation, Madison, USA) or Nucleon ${ }^{\mathrm{nt}}$ BACC Genomic DNA
Extraction (Gen-Probe Life Sciences, Manchester, UK) kits and quantified by the picogreen assay. The DNA samples were whole-genome amplified by Primer Extension Preamplification [38] before genotyping on the Sequenom IPLEX genotyping platform (Sequenom Inc., San Diego, USA) [39]. Polymorphism sequence information was downloaded from Ensembl (http://www.ensembl.org) and reformatted for the assay design process (www. sequenom.com). Multiplex design for the iPLEX methodology was then undertaken using the MassARRAY ${ }^{\circ}$ Assay Design v3.1 Software and the resulting multiplexes tested using a panel of CEPH and YRI HapMap DNAs. Thirty-four malaria candidate polymorphisms in various genes including GBP7, DARC, CR1, C6, CTL4, NOD1, CD36, CFTR, ABO, HBB, HbC, TRIM5, RTN3, SPTB, ADCY9, ADORA2B, NOS2, EMR1, ICAM1, GNAS, $D E R L 3, C D 40 L G$ and G6PD were genotyped in 971 cases and 891 controls. The SNPs were compiled on the basis of a review of reports of associations with severe malaria or association with other infectious diseases. The haemoglobin variant $S$ (HbS) polymorphism, known to be strongly associated with severe malaria $[25,40]$ was also genotyped. Genotype calling was performed using the Sequenom Spectro-typer software, an automated algorithm, followed by a careful visual inspection of the genotype cluster plots to assess quality. All the assays were quality filtered (call rate $>90 \%$ ) and assessed for evidence of genotypic deviation from Hardy-Weinberg equilibrium $(\mathrm{HWE})$ in the controls $(\mathrm{P}<0.001)$, indicative of genotyping error [41].

\section{Data analyses}

Statistical analyses were performed using IBM SPSS Statistics 17.0 (IBM Corporation, NY, USA) and the R software package (http://www.r-project.org). Genotypic deviations from HWE were assessed using a Chi-square statistical test. Case-control association analysis of SNP alleles and genotypes was undertaken by logistic regression with self-reported ethnicity age, sex and the $\mathrm{HbS}$ polymorphism included as covariates. Adjustment for self-reported ethnicity has been found to be a robust approach to controlling the potentially confounding effects of population structure [25]. Performing multiple statistical tests can lead to an increased chance of false positives. Also, as there are multiple polymorphisms in some genes, some statistical tests will be correlated. Thus, for the genetic results, a simulation was performed by permuting the phenotypes 10000 times to establish a significance cut-off, and found a threshold of $p \leq 0.01$ to be equivalent to a nominal false positive rate of $5 \%$.

\section{Results}

A total of 971 cases and 891 controls were enrolled into the study. The mean age ( \pm standard deviation) of the 
cases and control children was $55.4 \pm 37.9$ and $87.7 \pm$ 22.9 months respectively. The basic demographic characteristics of the study population (Figure 1) indicates a fairly gender balanced distribution in the cases [453 (46.7\%) females vs. 516 (53.3\%) males] that were enrolled mainly from the South West region [515 (53.3\%)] and from the Semi-Bantu [416 (50.0\%)] and Bantu [385 (46.3\%)] ethnic groups. The most prevalent clinical phenotypes included severe malaria anaemia [n (\%), 248 (21.8)], uncomplicated malaria [252 (22.1)], hyperpyrexia [116 (15)], hyperparasitaemia [58 (6.5)] and cerebral malaria [51 (5.4)].

Three polymorphisms were removed from the analysis because they were monomorphic (7:080302110, rs33950507, rs1799969) while two of the assays did not pass the quality filters (call rate $>90 \%$, rs 8176719 , rs33930165), leaving 30 SNPs that could be analysed for their association with malaria phenotype (Table 1). There was no evidence of genotypic deviation from HWE in the controls $(p>0.06)$. Additional file 1 shows the minimum $\mathrm{p}$-values from allelic/genotypic tests applied to the autosomal SNPs, and confirms that the sickle cell (HbS) polymorphism (rs334) was significantly associated with protection from malaria infection [AT $v s$. AA/TT, odds ratio $(\mathrm{OR})=0.29,95 \% \mathrm{CI} 0.21-0.42, \mathrm{p}=4.95 \times 10^{-13}$ ] and from SMA [AT vs. AA/TT, OR $=0.34,95 \% \mathrm{CI} 0.13-$ 0.93, $\mathrm{p}=0.024$ ] (Table 2).

The presence of the rs2297518 SNP in the gene encoding NOS2 was associated with protection from malaria infection (GG vs. AG $v s$. AA, OR $=0.52,95 \% \mathrm{CI}$ $0.36-0.75, \mathrm{p}=0.0005$ ) (Additional file 1). In addition, individuals with the AG genotype of this SNP were protected from anaemia $(\mathrm{OR}=0.49,95 \% \mathrm{CI} 0.35-0.70$, $\left.\mathrm{p}=6.32 \times 10^{-5}\right)$ and $\mathrm{UM}(\mathrm{OR}=0.50,95 \% \mathrm{CI} 0.29-0.84$, $\mathrm{p}=0.007$ ) (Table 2). Furthermore, individuals with the rs10775349 SNP of $A D C Y 9$ were protected from hyperpyrexia (CC vs. CG vs. GG, OR =0.02, 95\%CI 0.01-0.04, $\mathrm{p}=1.35 \times 10^{-87}$ ) while heterozygosity for the rs8176746 $\mathrm{SNP}$ in the $A B O$ locus was associated with protection against hyperparasitaemia (AC vs. AA/CC, $\mathrm{OR}=0.41$, 95\%CI 0.18-0.93, p=0.019) (Table 2 and Additional file 2). Nevertheless, a number of marginal protective genotype associations were also observed between specific gene mutations and anaemia (CFTR, GNAS), hyperparasitaemia (DERL3, GBP7), hyperpyrexia $(G B P 7, A B O)$ and SMA (HbS, ADCY9) (Table 2).

Male hemizygotes of G6PD rs1050828 (OR $=3.01$, 95\% CI 1.26-7.18, $\mathrm{p}=0.009)$ and females with rs1050828 (CT/TT vs. CC, OR = 2.47, 95\%CI 1.34-4.56, $\mathrm{p}=0.003$ ) and rs1050829 (CT/TT vs. CC, OR $=1.88,95 \%$ CI 1.20 2.93, $\mathrm{p}=0.005)$ SNPs of G6PD were more susceptible to anaemia (Table 2). Heterozygous GT and CT individuals for the rs373533 (GT vs. GG/TT, OR $=1.86,95 \%$ CI 1.22-2.84, $\mathrm{p}=0.003$ ) and $\mathrm{rs} 461645$ (CT vs. CC/TT,
$\mathrm{OR}=1.75$, 95\%CI 1.15-2.67, $\mathrm{p}=0.008)$ SNPs respectively in the EMR1 gene were more likely to develop hyperpyrexia. Furthermore, individuals with the RTN3 rs542998 SNP (additive C, OR $=1.47$, 95\%CI 1.09-1.99, $\mathrm{p}=0.011$ ) were also independently associated with susceptibility to hyperpyrexia (Table 2, Additional file 2). Even so, a number of marginal susceptibility genotype associations were also observed between specific gene mutations and anaemia (GBP7), CM (CD4OLG), hyperparasitaemia (NOS2), hyperpyrexia (CD36, CD40LG, G6PD), SMA (EMR1) and UM (NOS2, EMR1) (Table 2).

Additional file 2 shows that some polymorphisms were associated with severe malaria only in individuals from the Semi-Bantu ethnic group. The sickle cell trait was significantly associated with protection from SMA [AT vs. $\mathrm{AA} / \mathrm{TT}, \mathrm{OR}=0.33,95 \% \mathrm{CI} 0.16-0.72, \mathrm{p}=0.003$ ] while individuals with the EMR1 rs461645 TT and NOS2 rs8078340 CT genotypes were more susceptible to SMA $(\mathrm{OR}=2.79,95 \% \mathrm{CI} 1.30-6.02, \mathrm{p}=0.007)$ and hyperparasitaemia $(\mathrm{OR}=2.91,95 \% \mathrm{CI} 1.24-6.83, \mathrm{p}=0.012)$ respectively. Conversely, the association between G6PD rs1050828 with anaemia in females $(\mathrm{OR}=4.77,95 \% \mathrm{CI} 1.80-14.21, \mathrm{p}=$ 0.003) was only observed in the Bantu ethnic group.

Plasma TGF- $\beta$ levels were strongly correlated with heterozygosity for the $A D C Y 9$ rs2230739 ( $\mathrm{p}=0.039)$ and $H B B$ rs334 ( $\mathrm{p}=0.002$ ) SNPs (Figure 2). Individuals with the AG genotype of the ADCY9 gene had significantly higher levels of TGF- $\beta$ compared to their AA and GG counterparts. Similarly, levels of the cytokine were higher in the AT heterozygotes of rs334 compared to their AA counterparts. Plasma IL-10 levels were also correlated with heterozygosity for the $A B O \operatorname{rs} 8176746$ ( $\mathrm{p}=0.011$ ), with $\mathrm{AC}$ genotypes, however, having lower levels of the cytokine compared to their AA and CC counterparts. Nevertheless, no other SNPs were associated with levels of these cytokines.

\section{Discussion}

The clinical outcome of human malaria infection is highly variable and heterogeneous, depending on many factors including age, transmission intensity, parasite strain virulence, co-infections with other pathogens, socio-economic status as well as the genetic background of the human host [40]. The human genome has, therefore, evolved under selective pressure exerted by pathogens, with human genetics thought to explain $25 \%$ of the inter-individual variation in susceptibility to and manifestation of malaria attributable to various host factors [3]. This natural selection process is epitomized in the historical exposure to falciparum malaria and its association with the $\beta$-globin SNP underlying the haemoglobin S sickle-cell trait [42]. This mutant allele, the strongest known resistance genetic factor, can reach a frequency of $25 \%$ in some populations in Sub-Saharan 
Table 1 Minor allele frequencies and test of Hardy-Weinberg equilibrium in selected candidate SNPs

\begin{tabular}{|c|c|c|c|c|c|c|c|}
\hline \multirow[t]{2}{*}{ Gene } & \multirow[t]{2}{*}{ Alternate SNP name } & \multirow[t]{2}{*}{ SNP } & \multirow[t]{2}{*}{ Location } & \multicolumn{3}{|c|}{ Minor allele frequency } & \multirow{2}{*}{$\begin{array}{c}\mathrm{HWE}^{\dagger} \\
\text { (P value) }\end{array}$} \\
\hline & & & & Maj/Min & $\begin{array}{c}\text { Cases } \\
(n=971)\end{array}$ & $\begin{array}{l}\text { Controls } \\
(n=891)\end{array}$ & \\
\hline $\mathrm{HBB}$ & $\mathrm{HbS}$ & rs334 & Genic & $A / T$ & 0.054 & 0.088 & 0.189 \\
\hline GBP7 & & rs1803632 & $P$ & $C / G$ & 0.474 & 0.497 & 0.074 \\
\hline DARC & & rs2814778 & UTR & $A / G$ & 0.006 & 0.003 & 1.000 \\
\hline CR1 & & rs17047660 & UTR & $A / G$ & 0.283 & 0.301 & 0.409 \\
\hline CR1 & & rs17047661 & Genic & $\mathrm{G} / \mathrm{A}$ & 0.277 & 0.272 & 0.379 \\
\hline C6 & & rs1801033 & Genic & $A / C$ & 0.415 & 0.417 & 0.515 \\
\hline CTL4 & & rs 2242665 & Genic & $A / G$ & 0.319 & 0.324 & 0.642 \\
\hline NOD1 & & rs2075820 & $P$ & $\mathrm{G} / \mathrm{A}$ & 0.401 & 0.397 & 0.170 \\
\hline CD36 & & rs3211938 & Genic & $T / G$ & 0.144 & 0.148 & 0.409 \\
\hline CFTR & & rs17140229 & Genic & $C / T$ & 0.401 & 0.408 & 0.129 \\
\hline$A B O$ & & rs8176746 & Genic & C/A & 0.166 & 0.170 & 0.173 \\
\hline TRIM5 & & rs7935564 & Genic & $\mathrm{G} / \mathrm{A}$ & 0.486 & 0.486 & 0.273 \\
\hline RTN3 & & rs542998 & Genic & $C / T$ & 0.379 & 0.384 & 0.375 \\
\hline SPTB & & rs229587 & Genic & $\mathrm{T} / \mathrm{C}$ & 0.290 & 0.291 & 0.669 \\
\hline ADCY9 & & rs2230739 & Genic & $A / G$ & 0.092 & 0.104 & 0.434 \\
\hline ADCY9 & & rs10775349 & Genic & $C / G$ & 0.151 & 0.169 & 0.462 \\
\hline ADORA2B & & rs2535611 & Genic & $\mathrm{T} / \mathrm{C}$ & 0.099 & 0.110 & 0.715 \\
\hline NOS2 & & rs2297518 & Genic & $\mathrm{G} / \mathrm{A}$ & 0.105 & 0.139 & 0.552 \\
\hline NOS2 & NOS2-954 & rs1800482 & UTR & $\mathrm{G} / \mathrm{C}$ & 0.082 & 0.080 & 0.812 \\
\hline NOS2 & & rs9282799 & UTR & $C / T$ & 0.040 & 0.036 & 0.076 \\
\hline NOS2 & NOS2-1659 & rs8078340 & UTR & $C / T$ & 0.270 & 0.280 & 0.200 \\
\hline EMR1 & & rs373533 & Genic & $\mathrm{G} / \mathrm{T}$ & 0.444 & 0.463 & 0.942 \\
\hline EMR1 & & rs461645 & Genic & $C / T$ & 0.446 & 0.468 & 1.000 \\
\hline ICAM1 & ICAM-1 codon469 & rs5498 & Genic & $A / G$ & 0.119 & 0.141 & 0.238 \\
\hline GNAS & GNAS_8386 & rs8386 & Genic & $C / T$ & 0.159 & 0.154 & 0.224 \\
\hline DERL3 & & rs1128127 & Genic & $A / G$ & 0.464 & 0.457 & 0.481 \\
\hline $\mathrm{CD}_{40 L G}(\mathrm{~F})$ & & rs3092945 & $P$ & $\mathrm{~T} / \mathrm{C}$ & 0.295 & 0.269 & 0.359 \\
\hline $\mathrm{CD} 40 \mathrm{LG}_{(\mathrm{M})}$ & & rs3092945 & $P$ & $\mathrm{~T} / \mathrm{C}$ & 0.295 & 0.257 & $<0.001$ \\
\hline $\mathrm{CD} 40 \mathrm{LG}(\mathrm{F})$ & & rs1126535 & Genic & $\mathrm{T} / \mathrm{C}$ & 0.188 & 0.161 & 0.190 \\
\hline $\mathrm{CD} 40 \mathrm{LG}_{(\mathrm{M})}$ & & rs1126535 & Genic & $\mathrm{T} / \mathrm{C}$ & 0.159 & 0.216 & $<0.001$ \\
\hline $\mathrm{G} \mathrm{PD} \mathrm{F}_{(\mathrm{F})}$ & & rs1050829 & P & $\mathrm{T} / \mathrm{C}$ & 0.360 & 0.333 & 0.342 \\
\hline $\mathrm{G} \mathrm{PD} \mathrm{D}_{(\mathrm{M})}$ & & rs1050829 & P & $\mathrm{T} / \mathrm{C}$ & 0.360 & 0.341 & $<0.001$ \\
\hline $\mathrm{G} \mathrm{PD}_{(\mathrm{F})}$ & & rs1050828 & P & $C / T$ & 0.031 & 0.089 & 0.711 \\
\hline $\mathrm{G} \mathrm{PD}_{(\mathrm{M})}$ & & rs1050828 & P & $C / T$ & 0.120 & 0.106 & $<0.001$ \\
\hline
\end{tabular}

UTR $3^{\prime}$ untranslated region, $P$ promoter, Maj/Min = Major/Minor allele, $\mathrm{M}=$ male, $\mathrm{F}=$ Female ${ }^{\dagger}$ One degree of freedom $X 2$ test of HWE applied to the 891 controls.

Africa [40] yet explains only $2 \%$ of the total variation [3]. Many unknown protective genes thus exist, each presumably individually having small population effects.

Genetic association studies utilising polymorphic markers in candidate genes have been successful in identifying a number of genes that are associated with susceptibility to malaria, or severe malaria. A large case-control study of severe malaria in children across different regions and major ethnic groups in Cameroon has the potential to confirm previously reported malaria/genetic associations or permit the identification of new ones following the assessment of association of SNPs of human genes with clinical 
Table 2 Genotype associations between selected SNP and syndromes of malaria

\begin{tabular}{|c|c|c|c|c|c|c|c|c|}
\hline \multirow{2}{*}{$\begin{array}{c}\text { Phenotype } \\
\text { Anemia }\end{array}$} & \multirow{2}{*}{$\begin{array}{l}\text { Gene } \\
\mathrm{hHbS}\end{array}$} & \multirow{2}{*}{$\begin{array}{l}\text { SNPs } \\
\text { rs334 }\end{array}$} & \multirow{2}{*}{$\begin{array}{c}\text { Model } \\
\text { Heterozygous }\end{array}$} & \multirow{2}{*}{$\begin{array}{c}\text { Genotypes } \\
\text { AT vs. AA/TT }\end{array}$} & \multirow{2}{*}{$\begin{array}{c}\text { OR } \\
0.50\end{array}$} & \multicolumn{2}{|c|}{$95 \% \mathrm{Cl}$} & \multirow{2}{*}{$\frac{\text { P value }^{\text {f }}}{0.004}$} \\
\hline & & & & & & 0.31 & 0.80 & \\
\hline & GBP7 & rs1803632 & Heterozygous & CG vs. GG/CC & 1.42 & 1.05 & 1.91 & 0.023 \\
\hline & CFTR & rs17140229 & Additive & TT vs. CT vs. CC & 0.78 & 0.62 & 0.97 & 0.026 \\
\hline & NOS2 & rs2297518 & Heterozygous & AG vs. AA/GG & 0.49 & 0.35 & 0.70 & $6.32 \times 10^{-5}$ \\
\hline & GNAS & rs8386 & Heterozygous & CT vs. TT/CC & 0.67 & 0.47 & 0.95 & 0.024 \\
\hline & $\mathrm{G} \mathrm{PD} \mathrm{D}_{(\mathrm{F})}$ & rs1050828 & Dominant & $\mathrm{CT} / \mathrm{TT}$ vs. CC & 2.47 & 1.34 & 4.56 & 0.003 \\
\hline & $\mathrm{G} \mathrm{PD}_{(\mathrm{M})}$ & rs1050828 & Recessive & CC vs. CT/TT & 3.01 & 1.26 & 7.18 & 0.009 \\
\hline & $\mathrm{G} \mathrm{PD}_{(\mathrm{F})}$ & rs1050829 & Dominant & $\mathrm{CT} / \mathrm{TT}$ vs. CC & 1.88 & 1.20 & 2.93 & 0.005 \\
\hline \multirow[t]{2}{*}{ CM } & $\mathrm{CD}_{40 L G_{(F)}}$ & rs3092945 & Additive & TT vs. CT vs. CC & 4.03 & 1.19 & 13.79 & 0.021 \\
\hline & $\mathrm{CD} 40 \mathrm{LG}_{(\mathrm{M})}$ & rs3092945 & Additive & TT vs. CT vs. CC & 4.03 & 1.18 & 13.79 & 0.021 \\
\hline \multirow[t]{4}{*}{ Hyperparasitaemia } & GBP7 & rs1803632 & Dominant & CG/CC vs. GG & 0.53 & 0.29 & 0.96 & 0.041 \\
\hline & $\mathrm{ABO}$ & rs8176746 & Heterozygous & AC vs. AA/CC & 0.41 & 0.18 & 0.93 & 0.019 \\
\hline & NOS2 & rs8078340 & Heterozygous & CT vs. CC/TT & 1.80 & 1.01 & 3.21 & 0.046 \\
\hline & DERL3 & rs1128127 & Recessive & AA vs. GA/GG & 0.45 & 0.21 & 0.98 & 0.029 \\
\hline \multirow[t]{9}{*}{ Hyperpyrexia } & GBP7 & rs1803632 & Additive & GG vs. CG vs. CC & 0.73 & 0.55 & 0.99 & 0.042 \\
\hline & CD36 & rs3211938 & Recessive & GG vs. GT/TT & 2.80 & 1.20 & 6.51 & 0.027 \\
\hline & $A B O$ & rs8176746 & Heterozygous & $A C$ vs. AA/CC & 0.61 & 0.37 & 1.01 & 0.045 \\
\hline & RTN3 & rs542998 & Additive & TT vs. CT vs. CC & 1.47 & 1.09 & 1.99 & 0.011 \\
\hline & ADCY9 & rs10775349 & Additive & CC vs. CG vs. GG & 0.02 & 0.01 & 0.04 & $1.35 \times 10^{-87}$ \\
\hline & EMR1 & rs373533 & Heterozygous & GT vs. GG/TT & 1.86 & 1.22 & 2.84 & 0.003 \\
\hline & EMR1 & rs461645 & Heterozygous & CT vs. CC/TT & 1.75 & 1.15 & 2.67 & 0.008 \\
\hline & $\mathrm{CD}_{40 L G_{(F)}}$ & rs3092945 & Dominant & CT/CC vs. TT & 1.96 & 1.01 & 3.83 & 0.044 \\
\hline & $\mathrm{G} \mathrm{PD} \mathrm{D}_{(\mathrm{M})}$ & rs1050829 & Recessive & CC vs. CT/TT & 1.84 & 1.06 & 3.20 & 0.033 \\
\hline \multirow[t]{3}{*}{ SMA } & $\mathrm{hHbS}$ & rs334 & Heterozygous & AT vs. TT/AA & 0.34 & 0.13 & 0.93 & 0.024 \\
\hline & ADCY9 & rs2230739 & Heterozygous & AG vs. GG/AA & 0.48 & 0.23 & 1.02 & 0.050 \\
\hline & EMR1 & rs461645 & Recessive & TT vs. CT/CC & 2.05 & 1.12 & 3.75 & 0.020 \\
\hline \multirow[t]{3}{*}{ UM } & NOS2 & rs 2297518 & Heterozygous & GA vs. GG/AA & 0.50 & 0.29 & 0.84 & 0.007 \\
\hline & NOS2 & rs1800482 & Recessive & GG vs. GC/CC & 7.94 & 1.06 & 59.50 & 0.043 \\
\hline & EMR1 & rs461645 & Additive & CC vs. CT vs. TT & 1.42 & 1.04 & 1.93 & 0.025 \\
\hline
\end{tabular}

${ }^{\ddagger}$ Additive, dominant, recessive and heterozygous advantage genotypic tests were performed, adjusted for age, sex, ethnicity and HbS, but only the most statistically significant result is presented. $U M=$ uncomplicated malaria.

phenotypes. This study focused on genes whose association with malaria remain controversial as well as those reportedly associated with susceptibility to other infectious diseases. This study suggests that the protective effect of the sickle cell trait may be linked to the raised level of TGF- $\beta$ and provides additional support for a role of $A B O$ and RTN3 against severe malaria. It further provides the first evidence that polymorphisms in NOS2 and EMR1 may be associated with mild malaria, G6PD with anaemia while SNPs in ADCY9 and EMR1 may be linked with severe malaria in the Cameroonian population. Data reported here provide additional understanding on human candidate genes that may contribute to malaria susceptibility, help define the basis of individual and population variation in susceptibility to the disease and thus eventually facilitate efforts to develop vaccines and treatments to fight this infectious disease. However, it is possible that an apparent association with malaria can arise from linkage disequilibrium between the typed SNP and a primarily associated polymorphism. Constructing a detailed map of polymorphisms around these candidate genes and describing a profile of linkage disequilibrium among them will be helpful to identify the causal variant(s). In addition, an appropriately designed family-based study may provide useful linkage information, have more power to detect association and allow haplotypes to be constructed with more confidence.

Although the CCTTT pentanucleotide microsatellite repeat in iNOS promoter is thought to play a key role in 

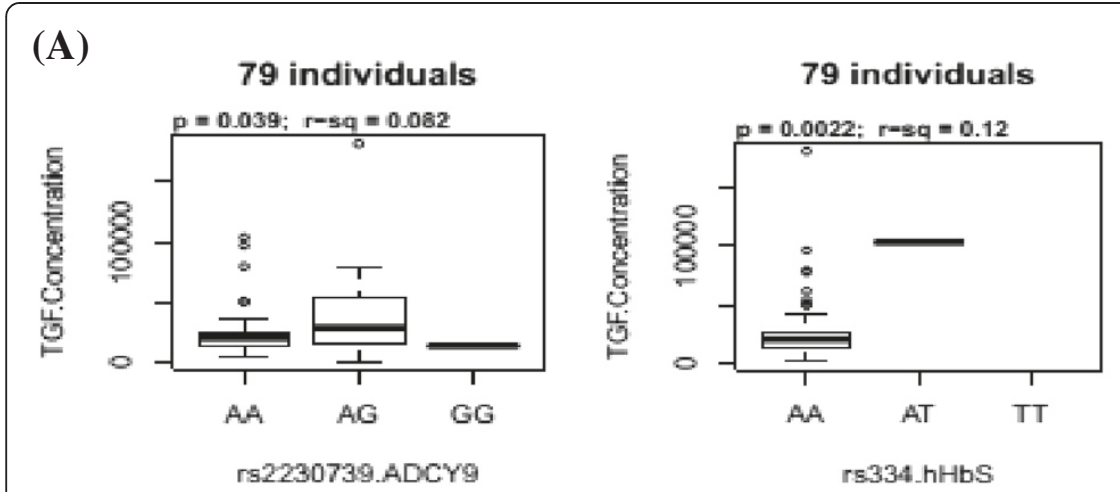

(B)

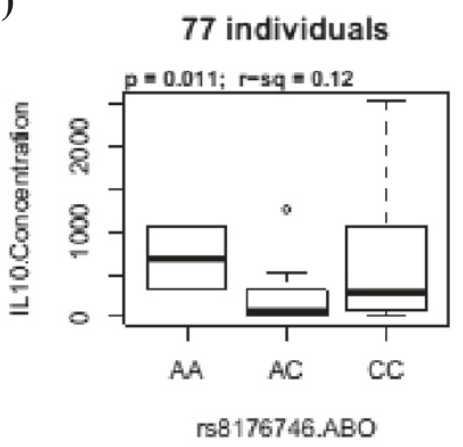

Figure 2 Association between human cytokine genetic polymorphisms and plasma cytokine levels (pg/ml). $\mathbf{A}=\mathrm{TGF}-\beta$ and $\mathbf{B}=\mid \mathrm{L}-10$.

the pathogenesis of severe malaria [43], the protective effects for NOS2 SNP is quite interesting since, no previous associations between rs2297518 and malaria have been reported. The SNP has, however, been linked with non-Hodgkin lymphoma [44] and inflammatory bowel disease [45]. It is possible that the SNP may increase the binding affinity to the mutant relative to the wild-type sequence thereby increasing the basal NOS activity and subsequent parasite killing by NO [15]. Parasites are thought to invade the liver, provoking a cytokine (e.g. IFN- $\gamma$ ) response that will induce NOS 2 to produce NO. The constitutively high NOS activity in children with the rs2297518 A allele will provide an advantage in resisting hepatic parasite stages without the need for additional stimuli. Nitric oxide is also thought to be effective in reducing blood-stage parasite density by antibodydependent cellular inhibition [15] triggered by the ingestion of opsonised merozoites by activated monocytes. The latter may then release toxic products and NO acting on maturing intracellular and cytoadherent parasites to limit parasitaemia density.

Adenylate cyclase $(\mathrm{AC})$ type 9 gene $(A D C Y 9)$ is an interesting candidate gene since it is critical in neuronal signalling [46] and thus may be relevant in the pathogenesis of cerebral malaria. However, Toyota and colleagues reported only a weak association of $A D C Y 9$ gene variation with mood disorders. Although the gene has polymorphisms with large allele frequency differences $\left(F_{S T}\right)$ between HapMap YRI and CEPH, the reported rs10775349 association with hyperpyrexia is very interesting. Nevertheless, further work is needed to strengthen these findings.

The observed association between Epidermal growth factor-like module containing, mucin-like, hormone receptor-like (EMR)1 polymorphisms and hyperpyrexia, severe malaria anaemia and uncomplicated malaria is quite interesting. EMR1 is a macrophage marker and also a transmembrane glycoprotein present in peripheral blood mononuclear cells and presumably involved in cell-cell interactions and activation of consecutive messenger cascades [47]. Gene expression of EMR1 is increased in lipoatrophic subcutaneous abdominal adipose tissue of HIV patients with HAART-associated lipodystrophy compared to those without [48] but no genetic associations with malaria have previously been reported. There is a need to explore further the possible role of this gene in malaria pathogenesis.

Polymorphisms in the ABO blood group were associated with hyperparasitaemia and hyperpyrexia (albert marginal) but not with the other more prevalent phenotypes. Previous studies have shown that cerebral malaria cases are less likely to be of blood group $\mathrm{O}[49,50]$ but more likely to be of group AB in Sri Lanka [51] and type $A$ and $B$ in India [50] while reports from Gabon indicated reduced risk of severe malaria of blood group A individuals [52]. How, the heterozygotes remain refractory to extremely high parasitaemia and temperature levels is unclear. Further studies are required to elucidate the functional relevance of $A B O$ variants on cytokines level.

Functional studies have demonstrated that a host erythrocyte $G$ protein signal pathway may be a critical component in parasite invasion and that erythrocyte G-alpha-s protein and the malaria parasite interact at a cellular level [53]. It however remains unclear whether this interaction would impact on disease progression. The protective effect of rs8386 with anaemia observed in this study is in line with recent reports of an association between G-alpha-s gene (GNAS) polymorphisms with severe malaria [54], although the SNP was only significant in multi-locus associations.

Reticulon is thought to be involved in malaria pathogenesis since its gene expression significantly increases in malaria and other infections [11] while chloroquine affects its expression [55]. However, the association of rs542998 with hyperpyrexia is quite interesting since the SNP has recently been associated with malaria in a Tanzanian population [27]. Further studies are required 
to elucidate the role of this polymorphism with this and other syndromes of malaria.

Cytokine polymorphisms have previously been linked with their differential production and expression in malaria $[5,6]$, with variation in promoter sequences thought to alter specific transcription factor recognition sites, transcriptional activation and cytokine production [5]. However, the association between $\mathrm{HbS}$ rs334 and $A D C Y 9$ rs2230739 with plasma levels of transforming growth factor-beta as well as $A B O$ rs8176746 with interleukin-10 is quite interesting since resistance to severe malaria has been linked to the ability to produce these immunoregulatory cytokines $[21,23]$. How rs334 and rs8176746 affect TGF- $\beta$ and IL-10 expression respectively is unclear. Nonetheless, $A D C Y 9$ rs2230739 may act to upregulate TGF $\beta$ transcription, with the heterozygotes providing some selective advantage since the raised TGF- $\beta$ levels will down-regulate proinflammatory cytokines, such as TNF, and protect against severe malaria $[22,23]$. This, to our knowledge is the first report of such associations and thus needs to be explored further in different settings and with larger sample numbers. It should be noted that individual differences in the levels of the TGF- $\beta$ measured at a specific moment may not only result from host genetic factors predisposing to high or low production, but also for a great part from the physiological condition at that time, as well as from global immunity.

\section{Conclusions}

This study suggests that the protective effect of the sickle cell trait may be linked to the raised level of Transforming Growth Factor beta and provides additional support for a role of $A B O$ and RTN3 against severe malaria. It also provides the first evidence that polymorphisms in NOS2 and EMR1 may be associated with mild malaria, G6PD with anaemia while SNPs in $A D C Y 9$ and $E M R 1$ may be linked with severe malaria in the Cameroonian population. Polymorphisms in human genes have important implications for the outcome of paediatric malaria in Cameroon. Moreover using mild malaria clinical phenotypes may permit the identification of novel pathways in the early development of disease.

\section{Additional files}

Additional file 1: Allelic and genotype associations between selected SNPs and malaria. Genotypes were tested for Additive, dominant, recessive and heterozygous advantage and then adjusted for age, sex, ethnicity and $\mathrm{HbS}$, but only the most statistically significant result is presented.

Additional file 2: Genotype associations between selected SNP and syndromes of malaria in the two major ethnic groups. Genotypes were tested for Additive, dominant, recessive and heterozygous advantage and then adjusted for age, sex and $\mathrm{HbS}$, but only the most statistically significant result is presented.

\section{Competing interests}

The author(s) declare that they have no competing interests; that they had financial support from MalariaGEN, EVIMalaR and CANTAM for the submitted work; no financial relationships with any organizations that might have an interest in the submitted work; no other relationships or activities that could appear to have influenced the submitted work.

\section{Authors' contributions}

TOA, KAR, EAA, DPK conceived and designed the experiments. TOA, AJK, NC, RNM, ANN performed the experiments. TOA, TGC, MalariaGEN analysed the data. DPK, EAA, MalariaGEN, TGC contributed reagents, materials, analysis tools. TOA, AJK, NC, KAR, EAA wrote the paper. All authors read and approved the final version of the paper.

\section{Acknowledgements}

We thank the participants from the communities who made this study possible; and the healthcare workers who assisted with this work. The research leading to these results received funding from the European Community's Seventh Framework Programme (FP7/2007-2013) under grant agreement No. 242095 EVIMalaR and partial financial support from the Central Africa Network for Tuberculosis, HIV/AIDS and Malaria (CANTAM), funded by the European and Developing Countries Clinical Trials Partnership (EDCTP) as well as from MalariaGEN. TGC has received funding from the Medical Research Council (ref. MR/K000551/1) and Wellcome Trust (096249/Z/11/A). The MalariaGEN Project is supported by the Wellcome Trust (WT077383/Z/05/Z) and by the Foundation for the National Institutes of Health (566) as part of the Bill \& Melinda Gates' Grand Challenges in Global Health Initiative. The Resource Centre for Genomic Epidemiology of Malaria is supported by the Wellcome Trust (090770/Z/09/Z). This research was supported by the Medical Research Council (G0600718; G0600230). The Wellcome Trust also provides core awards to the Wellcome Trust Centre for Human Genetics (090532/Z/09/Z) and the Wellcome Trust Sanger Institute (098051).

\section{Author details}

${ }^{1}$ Department of Biochemistry and Molecular Biology, University of Buea, Buea, Cameroon. 'Department of Zoology and Animal Physiology, University of Buea, Buea, Cameroon. ${ }^{3}$ Department of Animal Biology and Physiology, University of Yaounde I, Yaounde, Cameroon. ${ }^{4}$ Department of Medical Laboratory Science, University of Buea, Buea, Cameroon. ${ }^{5}$ London School of Hygiene and Tropical Medicine, London, UK. ${ }^{6}$ Wellcome Trust Centre for Human Genetics, University of Oxford, Oxford, UK.

Received: 5 February 2014 Accepted: 7 June 2014

Published: 16 June 2014

\section{References}

1. WHO: World Malaria Report 2013. Geneva: World Health Organization. Available at http://www.who.int/malaria/publications/world_malaria_report_2013/report/ en/. Accessed 2014 Jan 16.

2. MalariaGEN: A global network for investigating the genomic epidemiology of malaria. Nature 2008, 456:732-738.

3. Mackinnon MJ, Mwangi TW, Snow RW, Marsh K, Williams TN: Heritability of malaria in Africa. PLoS Med 2005, 2:e340.

4. Knight JC, Keating BJ, Rockett KA, Kwiatkowski DP: In vivo characterization of regulatory polymorphisms by allele-specific quantification of RNA polymerase loading. Nat Genet 2003, 33:469-475.

5. Ouma C, Davenport GC, Were T, Otieno MF, Hittner JB, Vulule JM, Martinson J, Ong'echa JM, Ferrell RE, Perkins DJ: Haplotypes of IL-10 promoter variants are associated with susceptibility to severe malarial anemia and functional changes in IL-10 production. Hum Genet 2008, 124:515-524.

6. Apinjoh TO, Anchang-Kimbi JK, Njua-Yafi C, Mugri RN, Ngwai AN, Rockett KA, Mbunwe E, Besingi RN, Clark TG, Kwiatkowski DP, Achidi EA: Association of cytokine and toll-like receptor gene polymorphisms with severe malaria in three regions of Cameroon. PLoS One 2013, 8:e81071.

7. Williams TN: Human red blood cell polymorphisms and malaria. Curr Opin Microbiol 2006, 9:388-394.

8. Würzner R, Hobart MJ, Fernie BA, Mewar D, Potter PC, Orren A, Lachmann PJ: Molecular basis of subtotal complement C6 deficiency, A carboxy- terminally truncated but functionally active C6. J Clin Investigat 1995, 95:1877-1883.

9. van de Vosse E, Ali S, de Visser AW, Surjadi C, Widjaja S, Vollaard AM, van Dissel JT: Susceptibility to typhoid fever is associated with a 
polymorphism in the cystic fibrosis transmembrane conductance regulator (CFTR). Hum Genet 2005, 118:138-140.

10. Speelmon EC, Livingston-Rosanoff D, Li SS, Vu Q, Bui J, Geraghty DE, Zhao LP, McElrath MJ: Genetic association of the antiviral restriction factor TRIM5alpha with human immunodeficiency virus type 1 infection. J Virol 2006, 80:2463-71.

11. Griffiths MJ, Shafi MJ, Popper SJ, Hemingway CA, Kortok MM, Wathen A, Rockett KA, Mott R, Levin M, Newton CR, Marsh K, Relman DA, Kwiatkowski DP: Genomewide analysis of the host response to malaria in Kenyan children. J Infect Dis 2005, 191:1599-1611.

12. Bellamy R, Kwiatkowski D, Hill AV: Absence of an association between intercellular adhesion molecule 1, complement receptor 1 and interleukin 1 receptor antagonist gene polymorphisms and severe malaria in a West African population. Trans R Soc Trop Med Hyg 1998, 92:312-316.

13. Newbold C, Warn P, Black G, Berendt A, Craig A, Snow B, Msobo M, Peshu N, Marsh K: Receptor-specific adhesion and clinical disease in Plasmodium falciparum. Am J Trop Med Hyg 1997, 57:389-398.

14. Kun JF, Mordmuller B, Lell B, Lehman LG, Luckner D, Kremsner PG: Polymorphism in the promoter region of the inducible nitric oxide synthase gene and protection against malaria. Lancet 1998, 351:265-266.

15. Kun JF, Mordmuller B, Perkins DJ, May J, Mercereau-Puijalon O, Alpers M, Weinberg JB, Kremsner PG: Nitric oxide synthase 2(Lambarene) (G-954C), increased nitric oxide production, and protection against malaria. J Infect Dis 2001, 184:330-336.

16. Levesque MC, Hobbs MR, Anstey NM, Vaughn TN, Chancellor JA, Pole A, Perkins DJ, Misukonis MA, Chanock SJ, Granger DL, Weinberg JB: Nitric oxide synthase type 2 promoter polymorphisms, nitric oxide production, and disease severity in Tanzanian children with malaria. J Infect Dis 1999, 180:1994-2002.

17. Burgner D, Usen S, Rockett $K$, Jallow M, Ackerman H, Cervino A, Pinder M, Kwiatkowski DP: Nucleotide and haplotypic diversity of the NOS2A promoter region and its relationship to cerebral malaria. Hum Genet 2003, 112:379-386.

18. Hobbs MR, Udhayakumar V, Levesque MC, Booth J, Roberts JM, Tkachuk AN, Pole A, Coon H, Kariuki S, Nahlen BL, Mwaikambo ED, Lal AL, Granger DL, Anstey NM, Weinberg JB: A new NOS2 promoter polymorphism associated with increased nitric oxide production and protection from severe malaria in Tanzanian and Kenyan children. Lancet 2002, 360:1468-1475.

19. Linke A, Kühn R, Müller W, Honarvar N, Li C, Langhorne J: Plasmodium chabaudi chabaudi: differential susceptibility of gene-targeted mice deficient in IL-10 to an erythrocytic-stage infection. Exp Parasitol 1996, 84:253-263.

20. Chelimo K, Sumba PO, Kazura JW, Ofula AV, John CC: Interferon-gamma responses to Plasmodium falciparum liver-stage antigen-1 and merozoite surface protein-1 increase with age in children in a malaria holoendemic area of western Kenya. Malar J 2003, 2:37

21. Omer FM, Riley EM: Transforming growth factor beta production is inversely correlated with severity of murine malaria infection. $J$ Exp Med 1998, 188:39-48.

22. Perkins DJ, Weinberg JB, Kremsner PG: Reduced interleukin-12 and transforming growth factor-beta1 in severe childhood malaria: relationship of cytokine balance with disease severity. J Infect Dis 2000, 182:988-992.

23. Achidi EA, Apinjoh TO, Yafi CN, Besingi R, Anchang JK, Awah NW, TroyeBlomberg M: Plasma levels of tumour necrosis factor-alpha, interleukin-10, interleukin-12, macrophage inhibition factor and transforming growth factor-beta in children with severe and uncomplicated falciparum malaria. J Trop Dis 2013, 1:103.

24. Carpenter D, Abushama H, Bereczky S, Färnert A, Rooth I, Troye-Blomberg M, Quinnell R, Shaw MA: Immunogenetic control of antibody responsiveness in a malaria endemic area. Hum Immunol 2007, 68:165-169.

25. Jallow M, Teo YY, Small KS, Rockett KA, Deloukas P, Clark TG, Kivinen K, Bojang KA, Conway DJ, Pinder M, Sirugo G, Sisay-Joof F, Usen S, Auburn S, Bumpstead SJ, Campino S, Coffey A, Dunham A, Fry AE, Green A, Gwilliam R, Hunt SE, Inouye M, Jeffreys AE, Mendy A, Palotie A, Potter S, Ragoussis J, Rogers J, Rowlands K, et al: Genome-wide and fine-resolution association analysis of malaria in West Africa. Nat Genet 2009, 41:657-665.

26. Toure O, Konate S, Sissoko S, Niangaly A, Barry A, Sall AH, Diarra E, Poudiougou B, Sepulveda N, Campino S, Rockett KA, Clark TG, Thera MA Doumbo O, Collaboration with The MalariaGEN Consortium: Candidate
Polymorphisms and Severe Malaria in a Malian Population. Plos One 2012, 7:e43987.

27. Manjurano A, Clark TG, Nadjm B, Mtove G, Wangai H, Sepulveda N, Campino SG, Maxwell C, Olomi R, Rockett KR, Jeffreys A, MalariaGen C, Riley EM, Reyburn H, Drakeley C: Candidate human genetic polymorphisms and severe malaria in a Tanzanian Population. PLoS One 2012, 7:e47463.

28. Basco LK, Ngane VF, Ndounga M, Same-Ekobo A, Youmba J, Abodo RTO, Soula G: Molecular epidemiology of malaria in Cameroon. XXI. Baseline therapeutic efficacy of chloroquine, amodiaquine, and sulfadoxinepyrimethamine monotherapies in children before national drug policy change. Am J Trop Med Hyg 2006, 75:388-395.

29. Quakyi IA, Leke RGF, Befidi-Mengue R, Tsafack M, Bomba-Nkolo D, Manga L, Tchinda V, Njeungue E, Kouontchou S, Fogako J, Nyonglema P, Harun LT, Djokam R, Sama G, Eno A, Megnekou R, Metenou S, Ndoutse L, Same-Ekobo A Alake G, Meli J, Ngu J, Tietche F, Lohoue J, Mvondo JL, Wansi E, Leke R, Folefack A, Bigoga J, Bomba-Nkolo C, et al: The epidemiology of Plasmodium falciparum malaria in two Cameroonian villages: Simbok and Etoa. Am J Trop Med Hyg 2000, 63:222-230.

30. Manga L, Bouchite B, Toto JC, Froment A: Anopheles species and the transmission of malaria in the forest/savanna transition zone in central Cameroon. Bull Soc Path Exot 1997, 90:128-130.

31. Wanji S, Tanke T, Atanga SN, Ajonina C, Nicolas T, Fontenille D: Anopheles species of the Mount Cameroon region: biting habit, feeding behaviour and entomological inoculation rates. Trop Med Int Health 2003, 8:643-649.

32. Nkuo Akenji TK, Ajame EA, Achidi EA: An investigation of symptomatic malaria parasitaemia and anaemia in nursery and primary school children in Buea District Cameroon. Cen Afr J Med 2002, 48:1-4.

33. Achidi EA, Apinjoh TO, Mbunwe E, Besingi R, Yafi C, Awah NW, Ajua A, Anchang JK: Febrile status, malarial parasitaemia and gastro-intestinal helminthiases in schoolchildren resident at different altitudes, in southwestern Cameroon. Ann Trop Med Parasitol 2008, 102:103-118.

34. Bigoga JD, Manga L, Titanji VPK, Coetzee M, Leke RGF: Malaria vectors and transmission dynamics in coastal south-western Cameroon. Malar J 2007, 6:5.

35. Achidi EA, Apinjoh TO, Anchang-Kimbi JK, Mugri RN, Ngwai AN, Judith K, Anchang-Kimbi JK, Yafi CN: Severe and uncomplicated falciparum malaria in children from three regions and three ethnic groups in Cameroon: prospective study. Malar J 2012, 11:215.

36. WHO: Severe falciparum malaria. Trans R Soc Trop Med Hyg 2000, 94(1):S1-S90.

37. Rooth I, Perlmann H, Bjorkman A: Plasmodium falciparum reinfection in children from a holoendemic area in relation to seroreactivities against oligopeptides from different malarial antigens. Am J Trop Med Hyg 1991, 45:309-318

38. Zhang L, Cui X, Schmitt K, Hubert R, Navidi W, Arnheim N: Whole genome amplification from a single cell: implications for genetic analysis. Proc Nat Acad Sci USA 1992, 89:5847-5851.

39. Ross P, Hall L, Smirnov I, Haff L: High level multiplex genotyping by MALDI-TOF mass spectrometry. Nat Biotech 1998, 16:1347-1351.

40. Kwiatkowski DP: How malaria has affected the human genome and what human genetics can teach us about malaria. Am J Hum Gen 2005, 77:171-192.

41. Teo YY, Fry AE, Clark TG, Tai ES, Seielstad M: On the usage of HWE for identifying genotyping errors. Ann Hum Genet 2007, 71:701-704.

42. Allison AC: Protection afforded by sickle-cell trait against subtertian malarial infection. Br Med J 1954, 1:290-294.

43. Dhangadamajhi G, Mohapatra BN, Kar SK, Ranjit MR: The CCTTT pentanucleotide microsatellite in iNOS promoter influences the clinical outcome in P. falciparum infection. Parasitol Res 2009, 104:1315-1320.

44. Wang SS, Davis S, Cerhan JR, Hartge P, Severson RK, Cozen W, Lan Q, Welch R, Chanock SJ, Rothman N: Polymorphisms in oxidative stress genes and risk for non-Hodgkin lymphoma. Carcinogen 2006, 27:1826-1834.

45. Martin MC, Martinez A, Mendoza JL, Taxonera C, Diaz-Rubio M, FernandezArquero $\mathrm{M}$, de la Concha EG, Urcelay E: Influence of the inducible nitric oxide synthase gene (NOS2A) on inflammatory bowel disease susceptibility. Immunogenet 2007, 59:833-837.

46. Toyota T, Hattori E, Meerabux J, Yamada K, Saito K, Shibuya H, Nankai M, Yoshikawa T: Molecular analysis, mutation screening, and association study of adenylate cyclase type 9 gene (ADCY9) in mood disorders. Am J Med Genet 2002, 114:84-92. 
47. Baud V, Chissoe SL, Viegas-Pequignot E, Diriong S, N'Guyen VC, Roe BA, Lipinski M: EMR1, an unusual member in the family of hormone receptors with seven transmembrane segments. Genomics 1995, 26:334-344.

48. Sevastianova K, Sutinen J, Kannisto K, Hamsten A, Ristola M, Yki-Jarvine H: Adipose tissue inflammation and liver fat in patients with highly active antiretroviral therapy-associated lipodystrophy. Am J Physiol Endocrinol Metabol 2008, 295:85-91.

49. Panda AK, Panda SK, Sahu AN, Tripathy R, Ravindran B, Das BK: Association of $A B O$ blood group with severe falciparum malaria in adults: case control study and meta-analysis. Malar J 2011, 10:309.

50. Rout R, Dhangadamajhi G, Ghadei M, Mohapatra BN, Kar SK, Ranjit M: Blood group phenotypes $A$ and $B$ are risk factors for cerebral malaria in Odisha, India. Trans R Soc Trop Med Hyg 2012, 106:538-543.

51. Pathirana SL, Alles HK, Bandara S, Phone-Kyaw M, Perera MK, Wickremasinghe AR, Mendis KN, Handunnetti SM: ABO-blood-group types and protection against severe Plasmodium falciparum malaria. Ann Trop Med Parasitol 2005, 99:119-124.

52. Lell B, May J, Schmidt-Ott RJ, Lehman LG, Luckner D, Greve B, Matousek P, Schmid D, Herbich K, Mockenhaupt FP, Meyer CG, Bienzle U, Kremsner PG: The role of red blood cell polymorphisms in resistance and susceptibility to malaria. Clin Infect Dis 1999, 28:794-799.

53. Harrison T, Samuel BU, Akompong T, Hamm H, Mohandas N, Lomasney JW, Haldar K: Erythrocyte G protein-coupled receptor signaling in malarial infection. Science 2003, 301:1734-1736.

54. Auburn S, Diakite M, Fry AE, Ghansah A, Campino S, Richardson A, Jallow M, Sisay-Joof F, Pinder M, Griffiths MJ, Peshu N, Williams TN, Marsh K, Molyneux ME, Taylor TE, Koram KA, Oduro AR, Rogers WO, Rockett KA, Haldar K, Kwiatkowski DP: Association of the GNAS locus with severe malaria. Hum Genet 2008, 124:499-506.

55. Silveira $H$, Ramos $S$, Abrantes $P$, Lopes $L F$, do Rosario VE, Abrahamsen MS: Effect of chloroquine on gene expression of Plasmodium yoelii nigeriensis during its sporogonic development in the mosquito vector. Malar J 2007, 6:84.

doi:10.1186/1475-2875-13-236

Cite this article as: Apinjoh et al:: Association of candidate gene polymorphisms and TGF-beta/IL-10 levels with malaria in three regions of Cameroon: a case-control study. Malaria Journal 2014 13:236.

\section{Submit your next manuscript to BioMed Central and take full advantage of:}

- Convenient online submission

- Thorough peer review

- No space constraints or color figure charges

- Immediate publication on acceptance

- Inclusion in PubMed, CAS, Scopus and Google Scholar

- Research which is freely available for redistribution 